\title{
Seroprevalence, Knowledge and Behavioral Factors Associated with HIV Infection Among Men Who have Sex with Men (MSM) in Benin
}

\author{
Pepin Septime Hector Hessou ${ }^{1,4,6, *}$, Yolaine Glele-Ahanhanzo ${ }^{2}$, Clement Ahoussinou ${ }^{3}$, \\ Colette Sylvie Azandjeme ${ }^{2}$, Codjo Djignefa Dadje ${ }^{4}$, Wilfrid Bonou ${ }^{5}$, Virgile Capo-Chichi ${ }^{5}$, \\ Bruno Doussoh ${ }^{5}$, Michel Boko ${ }^{6}$, Michel Alary ${ }^{4}$ \\ ${ }^{1}$ Key Populations Department, National Reference Centre for AIDS Research and Care (CNRRPEC-CNHU/Bénin), Cotonou, Benin \\ ${ }^{2}$ Epidemiology and Biostatistics Department, Regional Institute of Public Health, University of Abomey-Calavi, Ouidah, Benin \\ ${ }^{3}$ Health Research Department, Institute of Analysis, Communication and Social Groups (INACES), Misserete, Oueme, Benin \\ ${ }^{4}$ Population Health and Best Practices in Health Axis Quebec City UHC Research Centre - Laval University, Saint-Sacrement Hospital, Quebec, \\ Canada \\ ${ }^{5}$ Research Department, Leadership \& Development (LEADDS), Cotonou, Benin \\ ${ }^{6}$ Inter-faculty Centre for Training and Research in Environment for Development, University of Abomey-Calavi (UAC), Calavi, Bénin
}

Email address:

shessou@yahoo.fr (P. S. H. Hessou), nyglele@yahoo.fr (Y. Glele-Ahanhanzo), clement.ahoussinou@gmail.com (C. Ahoussinou), colsyaz@yahoo.fr (C. S. Azandjeme), codjo-djignefa.djade.1@ulaval.ca (C. D. Dadje), w.bonou@gmail.com (W. Bonou), vcapochichi@gmail.com (V. Capo-Chichi),medessekb@yahoo.fr (B. Doussoh),bokomichel@gmail.com (M. Boko), michel.alary@crchudequebec.ulaval.ca (M. Alary)

${ }^{*}$ Corresponding author

To cite this article:

Pepin Septime Hector Hessou, Yolaine Glele-Ahanhanzo, Clement Ahoussinou, Colette Sylvie Azandjeme, Codjo Djignefa Dadje, Wilfrid Bonou, Virgile Capo-Chichi, Bruno Doussoh, Michel Boko, Michel Alary. Seroprevalence, Knowledge and Behavioral Factors Associated with HIV Infection Among Men Who have Sex with Men (MSM) in Benin. Central African Journal of Public Health.

Vol. 6, No. 2, 2020, pp. 95-105. doi: 10.11648/j.cajph.20200602.17

Received: February 17, 2020; Accepted: February 24, 2020; Published: March 3, 2020

\begin{abstract}
Most of HIV infections among adults in sub-Saharan Africa have been acquired through unprotected sex, including with sex workers and through sex between men. Unprotected sex between men promotes the transmission of STIs and HIV in particular. Unprotected anal penetration is a high-risk route of transmission. The study will estimate HIV prevalence and describe the risk factors associated among MSM population. From January to April 2016, 414 participants were enrolled in the study by the "Respondent-Driven Sampling"; the variables measured were biological, behavioral and HIV knowledge factors. Univariate and multivariate analysis were conducted and the results were weighted. MSM are predominantly young: 50.4\% (41.7- 59.2) are between 20 and 24 years old, the weighted HIV prevalence is $21.8 \%$ (95\% CI: $13.5-30.7)$. More than half of participants $54.4 \%$ (43.9 - 64.8) did not have accurate knowledge of HIV. Condom use during the last anal sex is significantly associated with HIV AOR (adjusted odd ratios) 0.47 (95\% CI: 0.36-0.62), $<<0.0001$ ) adjusted on potentially confounding factors. This is about those below 25 years AOR 0.7 (95\%CI: 0.55-0.90, p<0.0005), the educational level AOR 22.18 (95\% CI: 9.49-59.75, $<<0.0001$ ), living in couple, AOR: 2.01 (95\% CI: 1.54-2.63) p $<0.0001$; frequency of condom use with lubricant, AOR: 1.3 (95\% CI: 1.03-1.65, $\mathrm{p}<0.029)$. This study highlights a high HIV prevalence among the MSM population and therefore shows the need to develop specific high-impact prevention programs towards this key target group while promoting an environment of protection and respect for human right.
\end{abstract}

Keywords: HIV, Epidemiology, Men Sex Men, Risk Factors, Africa 


\section{Introduction}

In sub-Saharan Africa, the number of new HIV infections remains high [1, 2]. Worldwide, 36.7 million people are living with HIV and 1.8 million people were infected with HIV in 2016, including 600,000 and 370,000 people respectively in West and Central Africa [3]. As for target populations and their sexual partners, they are responsible for $47 \%$ of new HIV infections worldwide, and $16 \%$ of new HIV infections in Eastern and Southern Africa [2, 3].

Although the HIV epidemic varies considerably from one country or region to another, Sub-Saharan Africa remains the most affected region, with nearly 1 in 20 adults $(4.9 \%)$ living with HIV and representing $69 \%$ of people living with HIV worldwide [4]. Most of HIV infections among adults in sub-Saharan Africa have been acquired through unprotected sex, including with sex workers and during sex between men [1]. Unprotected sex between men promotes the transmission of STIs and HIV in particular; unprotected anal penetration is a high-risk route of transmission $[2,4,5]$ The risk of contracting HIV is 27 times higher among men who have sex with men (MSM); [2,6]. A meta-analysis of monitoring data from low- and middle-income countries, found that MSM are 19.3 times more likely to be infected with HIV than people in the general population. The same source reveals that the incidence of HIV infection among MSM ranges from 1.2 to 14.4 per 100 people per year [4, 5] Recent studies conducted in sub-Saharan Africa and reported in the UNAIDS report found among MSM, HIV prevalence ranging from $6 \%$ to $37 \%[4,5]$.

Like most countries in the sub-Saharan sub-region, homosexuality is considered an "illegal" practice in Benin, and sex between men is perceived as a social deviance $[7,8]$. This situation exposes MSM to stigma and discrimination and makes them particularly vulnerable to violence of all kinds [8,9]. Benin is a mixed epidemic country that has conducted very few scientific studies on the dynamics of the epidemic among HIV targets: injecting-drug users (IDUs) and MSM [11-13]. However, it has studies on HIV transmission patterns at the level of key populations (MoT) $[6,14]$. MSM populations remain a concern of the national response to HIV infection. Therefore, they are part of the key targets of the various national HIV strategic plans in Benin [15]. The purpose of this study is to determine the prevalence of HIV infection and to analyze behavioral factors and knowledge associated with HIV.

\section{Methods}

\subsection{Type and Scope of the Study}

This is a cross-sectional study carried out from December 2015 to March 2016. The sites covered were primarily located in the principal cities of the departments, particularly those selected in the study entitled: Analysis of the situation of MSM and IDUs in the fight against STI/HIV/AIDS in Benin in 2012 [10]. In order to take part in the study, one must be a biological male aged at least 18 , and must have had at least once anal (receptive or insertive) or oral (fellation and/or anilingus) sex with a male partner over the 12 months preceding the survey.

\subsection{Sampling Method}

The sampling method, known as "respondent-driven sampling" (RDS), is also called respondent-determined sampling or snowballing sampling [16-19]. This method is suitable for recruiting hidden or stigmatized populations. First of all, it consisted in choosing, in a reasoned manner, the first participants as the starting point of the recruitment chain. They are called "Seeds". They have been selected to participate in the study mainly for their ability to recruit and mobilize people from their networks. They were diversified according to age and socio-economic conditions [19]. These first nine (09) respondents, after their interview, recruited other people. This first set of respondents recruited by the first participants in the survey constitutes the first wave. This first wave engaged in turn, other people who will constitute the second wave of participants and so on until the sample size is reached.

After the interview, each respondent received serial numbered coupons called "reference coupons". These coupons will be used by a MSM who has already been interviewed and who refers some of his peers to participate in the survey. The recruited person keeps this coupon and shows it before participating in the survey. Each participant has received three serial numbered recruitment coupons to be given to his peers individually known to him and homosexuals or bisexuals. When a coupon was rejected, the recruiter completed a rejection questionnaire to assess the conditions for refusal and then identified a replacement in order to match the sample size. Reference numbers and coupons will not allow identifying respondents. The interviews took place in specific adapted sites selected for the study. The first respondents called recruiters or "Seeds" are in compliance with the heterogeneity principle of the sample. To achieve this, the research team ensured beforehand that all categories of MSM have been taken into account during the first recruitment, particularly homosexuals and bisexuals (active, passive or versatile). A second coupon serves as travel expense reimbursement coupon. It's also called a receipt coupon or simply a receipt. It's kept by the recruiter who uses it to claim travel expenses. These fees, which are fixed at a flat rate, range from $\$ 2$ to $\$ 10$, depending on places of recruitment and interview.

\subsection{Sample Size}

The calculation of the number of subjects required for the study was made on the basis of the following estimates: for an HIV prevalence of $17 \%$ and an accuracy of $5 \%$, with a confidence interval of $95 \%$ of the expected prevalence that varies between $10 \%$ and $30 \%$, and a cluster effect of 2 [6]. The estimated sample size is 434 MSM [20]. 


\subsection{Data Collection}

A standardized, pre-tested and structured questionnaire was used to collect data [21-23]. It addressed socio-demographic characteristics, including level of education, sexual knowledge, behavior or practices, opinions and attitudes towards STIs and HIV/AIDS; types of sexual intercourses; use of condoms and lubricant gels; alcohol and drug use, voluntary testing and HIV.

Participation in HIV testing was not mandatory, but was strongly encouraged. At the end of the behavioral investigation and achievement of informed consent, trained laboratory technicians carried out the screening test at the study site, in accordance with national standards and procedures and also with references for the confirmation of positive or undetermined cases. Concerning the referrals, a partnership has been concluded with care sites within each city hosting the collection sites for the effective management of positive cases.

The HIV screening algorithm used is that of Strategy II recommended by WHO and UNAIDS, namely: Determine HIV1\&2® (3rd generation test) which is a first line and high sensitivity test and SD Bioline HIV1/2 which allows discrimination of HIV type for positive samples [12, 24, 25]. The results were shared with all MSM who gave their consent and accepted to know their HIV status with respect to ethical rules according to the Belmont report.

All the tests subjects were systematically taken on blotting paper for quality control, which was carried out in the reference laboratory of the Health Program for the Fight against AIDS.

\subsection{Variables}

The presence of anti-HIV antibodies was the dependent variable, it is a binary variable of being infected (HIV+) or not (HIV-).

The explanatory variable was the use of condoms and lubricant gels during the last anal intercourse, which is a dichotomous variable: Yes / No.

The other variables were socio-demographic, behavioral and knowledge-related variables.

Socio-demographic variables: age in years (less than 20 , 20-24, 25-29, 25-29, 30 and over), Marital status (Married/divorce, single), Living in couple (no, with a man, with a woman), Level of education (non-academic, primary, secondary, higher), Profession (Craftsman, Salesmann, civil servant, pupils/students), Type of homosexuality (homosexual, bisexual) Sexual role (active/insertive, passive/ receptive, versatile) Behavioral variables (frequency of condom use for these anal intercourse, age at first anal intercourse with a male partner, frequency of condom use with a lubricant, condom use during last anal intercourse with a male partner, drug consumption, Knowledge-related variables (knowledge of the serological status of your regular partner knowledge level of HIV infection, knowledge of the mode of transmission.
Complete/accurate knowledge of HIV is identified through a composite variable relating to the knowledge of two means of prevention and the rejection of three misconceptions by the targets [27-30]. These are 5 Yes/No binary variables. All MSM who answered properly all questions have a complete or accurate knowledge of HIV and the others do not.

\subsection{Data Processing and Analysis}

Data were input with version 3.1. of EPI DATA software. The clearance program automatically generated an error list that was corrected. The statistical analysis was performed with RDSAT, version 5.6 [31] and SPSS version 24.0. Homophily is an indicator for measuring the fact that seeds and recruiters prefer to recruit directly from their own group rather than randomly. It has been estimated with socio-demographic variables [31, 32].

Percentage comparisons were made with Pearson's Chi-square test or the exact Fisher test. Multivariable logistic regression was used to build measures estimated between the association of HIV infection and exposure to condom and gel use, according to potentially confounding variables. The multivariate model was constructed by using both literature data and descending order data with associations of variables with a $\mathrm{P}<20 \%$ which are: age at first intercourse, knowledge of HIV status, age, marital status, education level, living in couple, sexual orientation, All estimates were weighted according to network size.

\subsection{Ethical Considerations}

Ethical rules were respected during the enrolment process of MSM, in accordance with ethical provisions according to the ethical opinion issued by Comité National d'Ethique pour la Recherche en Santé (National Ethics Committee for Health Research). Thus, in addition to providing travel expenses, free condoms and lubricants were given to all participants. These various costs have been converted into a minimum fee which cannot constrain participation in the survey, nor motivate participants to engage in possible double participation biases, or to induce some of them to make misleading statements in order to circumvent the non-inclusion criteria.

\section{Results}

\subsection{Seed Characteristics}

The post-data clearance study identified 414 valid participants. Of the 434 participants initially enrolled, only 414 were selected in the study, that's. $95.40 \%$. Failures to enroll related to totally incomplete and/or double counting files (Table 1). The sizes of MSM seed social network range from 3 at Porto Novo site to 56 in second site of Cotonou (Figure 1). 
Table 1. Presentation of the characteristics of the study seeds (N-9) for RDS sampling.

\begin{tabular}{llllllllll}
\hline $\begin{array}{l}\text { Seed \& } \\
\text { Collection site }\end{array}$ & $\begin{array}{l}\text { Size of Social } \\
\text { Network }\end{array}$ & Age & $\begin{array}{l}\text { Sexual } \\
\text { preference }\end{array}$ & Sex role & Instruction & HIV Status & $\begin{array}{l}\text { Number of } \\
\text { recruits }\end{array}$ & $\begin{array}{l}\text { Number } \\
\text { of waves }\end{array}$ & $\begin{array}{l}\text { \%o of sample } \\
\text { (n=4141) }\end{array}$ \\
\hline 1Co & 41 & 26 & Bisexual & Insertive & Secondary & Positive & 64 & 4 & 15.46 \\
2Co & 1 & 20 & Homosexual & Insertive & Secondary & Positive & 11 & 3 & 2.66 \\
3Co & 56 & 24 & Homosexual & Receptive & Secondary & Negative & 80 & 4 & 19.32 \\
4PN & 3 & 25 & Bisexual & Receptive & Primary & Negative & 46 & 4 & 11.11 \\
5AC & 13 & 30 & Homosexual & Insertive & High & Negative & 43 & 4 & 10.40 \\
6AC & 06 & 22 & Homosexual & Receptive & High & Negative & 57 & 4 & 13.77 \\
7Oh & 44 & 25 & Homosexual & Receptive & High & Negative & 33 & 4 & 7.97 \\
8Boh & 52 & 24 & Bisexual & Insertive & Primary & Negative & 41 & 4 & 9.90 \\
9Pk & 06 & 23 & Homosexual & Receptive & High & Positive & 39 & 3 & 9.42 \\
\hline
\end{tabular}

$+\mathrm{Co}=$ city of Cotonou (3 seeds); AC: City of Abomey-Calavi (2 seeds); Oh: city of Ouidah (1 seed), PN: city of Porto Novo (1 seed); Boh: city of Bohicon (1 seed); Pk: city of Parakou (1 seed).

Regarding socio-demographic characteristics of MSM in the study, one in two MSM is under 25 years of age. 50.4\% (95\%CI: 41.7- 59.2), 52.83\% (95\%: 41.7 - 59.2) had their first anal sex with a male partner between 15 and 19 years of age. They are mostly single: $89.6 \%$ with a $95 \%$ CI from $82.7 \%$ to $96.7 \%$ (Table 2 ).

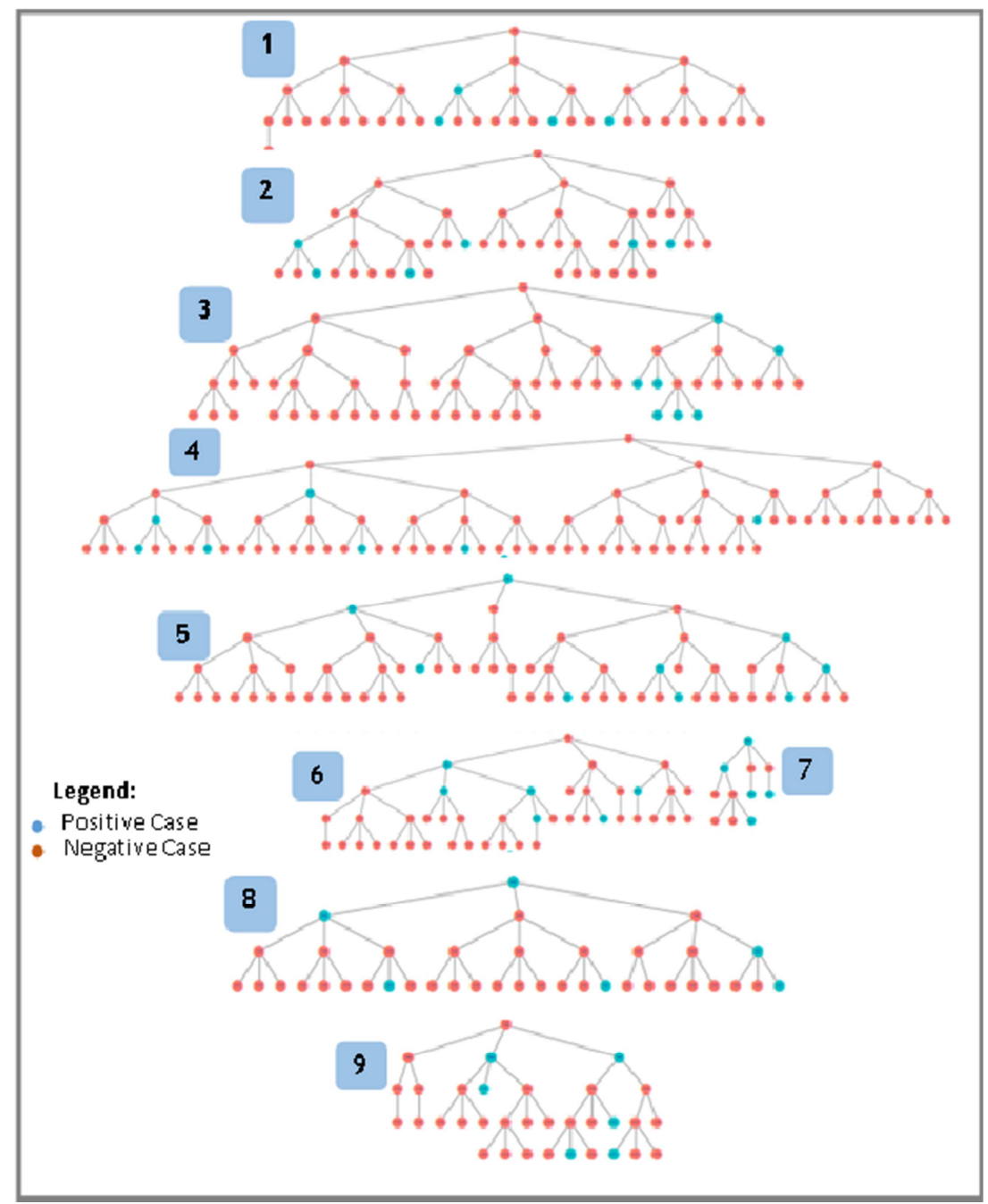

Figure 1. Graphic representation of different recruitment chains of MSM under RDS.

\subsection{Prevalence of HIV Infection}

The weighted prevalence of HIV infection is $21.8 \%$ (13.5 - 30.7). More than half of the participants $54.4 \%$ (43.9 - 64.8) didn't have good knowledge of HIV prevention and 13.3\% (6.7 - 19.9) think that apparently healthy person can't be HIV positive. Of the MSM surveyed, 46.2\% (37.6-54.7) consider the anal route as the sexual way with the highest risk for contracting HIV and 6.0\% (3.2-9.0) consume drugs (Table 3). 
Pepin Septime Hector Hessou et al: $\quad$ Seroprevalence, Knowledge and Behavioral Factors Associated with HIV Infection Among Men Who have Sex with Men (MSM) in Benin

Table 2. Descriptive characteristics of study participants.

\begin{tabular}{|c|c|c|c|c|}
\hline Variables & $\mathbf{n}$ & Unweighted (\%) & RDS-weighted (CI 95\%) & Homophily \\
\hline \multicolumn{5}{|l|}{ Age (years) } \\
\hline under 20 & 55 & 13.3 & $11.1(6.7-15.7)$ & 0.95 \\
\hline 20 to 24 & 215 & 51.9 & $50.4(41.7-59.2)$ & 0.90 \\
\hline 25 to 29 & 120 & 29.0 & $31.3(2.0-39.5)$ & 1.04 \\
\hline 30 and more & 24 & 5.8 & $7.1(2.2-12.0)$ & 0.60 \\
\hline \multicolumn{5}{|l|}{ Marital status } \\
\hline Married/divorced & 25 & 6.03 & $10.4(3.3-17.3)$ & 1.02 \\
\hline \multicolumn{5}{|l|}{ Living in couple } \\
\hline No & 295 & 71.26 & $69.2(60.7-77.7)$ & 1.07 \\
\hline Yes, with a man & 80 & 19.32 & $20.9(13.3-28.4)$ & 1.09 \\
\hline Yes, with a woman & 36 & 8.70 & $10.0(4.7-5.2)$ & 0.81 \\
\hline \multicolumn{5}{|l|}{ Educational level } \\
\hline Out-of-school & 8 & 1.93 & $0.7(0.1-1.3)$ & 0.86 \\
\hline Primary & 35 & 8.45 & $7.8(4.4-11.1)$ & 1.06 \\
\hline High level & 200 & 48.31 & $43.1(34.9-51.2)$ & 1.02 \\
\hline \multicolumn{5}{|l|}{ Profession } \\
\hline Craftsman & 98 & 23.67 & $22.6(15.7-29.6)$ & 1.10 \\
\hline Salesman & 22 & 5.31 & $4.6(1.9-7.4)$ & 0.96 \\
\hline Official & 47 & 11.35 & $13.1(7.4-18.7)$ & 1.06 \\
\hline Students & 247 & 59.66 & $59.7(51.1-68.1)$ & 1.05 \\
\hline \multicolumn{5}{|l|}{ Homosexuality Type } \\
\hline Homosexual & 260 & 62.8 & $56.4(45.9-66.8)$ & 1.01 \\
\hline Bisexual & 154 & 37.2 & $43.6(33.2-54.1)$ & 0.98 \\
\hline \multicolumn{5}{|l|}{ Sexual Role } \\
\hline Active/Insertive & 224 & 54.11 & $60.8(52.3-69.2)$ & 0.96 \\
\hline Passive/Receptive & 128 & 30.92 & $30.3(22.3-38.4)$ & 1.10 \\
\hline Versatile & 55 & 13.29 & $8.8(0.8-11.9)$ & 0.95 \\
\hline \multicolumn{5}{|c|}{ Age at first intercourse } \\
\hline $15-19$ years & 227 & 54.83 & $52.8(41.7-59.2)$ & 0.99 \\
\hline $20-24$ years & 187 & 45.17 & $47.2(38.4-55.9)$ & 0.99 \\
\hline No & 107 & 25.84 & $28.4(19.4-37.6)$ & 1.10 \\
\hline
\end{tabular}

\subsection{Level of Knowledge and HIV Risk Factors in MSM}

Table 3. Level of knowledge and HIV risk factors in MSM.

\begin{tabular}{|c|c|c|c|}
\hline Variables & $\mathbf{n}$ & Unweighted (\%) & RDS-weighted (CI 95\%) \\
\hline \multicolumn{4}{|c|}{ Sexual route with the highest risk of contracting HIV } \\
\hline Manual & 3 & 0.72 & $0.7(0.0-1.9)$ \\
\hline Oral & 12 & 2.90 & $2.1(0.6-3.6)$ \\
\hline Vaginal & 214 & 52.69 & $51.0(42.3-59.6)$ \\
\hline \multicolumn{4}{|c|}{ Complete/accurate knowledge of HIV } \\
\hline Yes & 155 & 39.3 & $45.6(35.2-56.1)$ \\
\hline No & 239 & 60.7 & $54.4(43.9-64.8)$ \\
\hline \multicolumn{4}{|l|}{ Sexual orientation } \\
\hline Active or insertive & 224 & 54.11 & $60.7(52.2-69.3)$ \\
\hline Passive or receptive & 128 & 30.92 & $30.4(22.3-38.5)$ \\
\hline Versatile (one or the other) & 55 & 13.29 & $8.9(5.9-11.8)$ \\
\hline \multicolumn{4}{|l|}{ Most risky type of anal sex } \\
\hline Anal active & 27 & 6.52 & $7.9(2.3-13.4)$ \\
\hline Anal passive & 210 & 50.72 & $52.6(43.7-61.5)$ \\
\hline Both have the same level of risk & 177 & 42.75 & $39.5(31.3-47.8)$ \\
\hline \multicolumn{4}{|c|}{ Liquids produced by the human body that can transmit HIV in men } \\
\hline Sperm & 389 & 93.96 & $96.5(94.6-98.5)$ \\
\hline Blood & 414 & 100.00 & $1.00(--)$ \\
\hline Saliva & 100 & 24.15 & $24.7(16.6-32.9)$ \\
\hline \multicolumn{4}{|l|}{ Gateways of HIV in men bodies } \\
\hline Sexual & 406 & 98.07 & $98.5(97.3-99.8)$ \\
\hline Blood & 402 & 97.10 & $97.1(95.0-99.1)$ \\
\hline Anal & 360 & 86.96 & $86.7(80.7-92.8)$ \\
\hline Oral & 228 & 55.07 & $60.0(51.7-68.2)$ \\
\hline Wounds & 329 & 79.47 & $76.6(68.8-84.3)$ \\
\hline
\end{tabular}




\begin{tabular}{llll}
\hline Variables & n & Unweighted (\%) & RDS-weighted (CI 95\%) \\
\hline Drug consumption & & & \\
Yes & 37 & 8.94 & $6.0(3.2-9.0)$ \\
No & 377 & 91.06 & $93.9(91.0-96.8)$ \\
Types of drugs (n=37) & 35 & 94.59 & $96.6(92.1-00.0)$ \\
Gue/Indian Hemp /cannabis & 2 & 5.41 & $3.4(3.0-4.1)$ \\
Cocaïne/Heroin & & \\
\hline
\end{tabular}

\subsection{Use of Condoms and Lubricating Gels}

MSM who used the condom every time when having anal sex, to protect themselves, were $89.3 \%(83.0$ - 96.0). But during the last anal sex with a man only 7 out of 10 , or $71.5 \%$ (63.3 - 80.0) use it. Percentage of condom use during the last vaginal or anal intercourse with a woman is $45.9 \%$ (37.2 54.6). The water-based lubricant is the most used with condoms by MSM, 66.2\% (57.3-75.1) (Table 4).

\subsection{Univariate and Multivariate Analysis}

Several socio-demographic variables have been associated with HIV infection (Table 5). It's the marital status (RDS-weighted OR: $0.15,95 \%$ CI: $0.15-0.18$ ), educational level (RDS-weighted OR: $2.15,95 \%$ CI: $1.67-2.81$ ), the fact that the MSM lives in couple (RDS- 95\%CI 1.21-1.59), full knowledge of HIV (RDS-weighted OR: 2.2, 95\% CI: 1.96 2.49). The final multivariate model included: condom use at last anal intercourse, age, marital status, education level, couple life, sexual orientation, age at first intercourse, testing and knowing the result. Condom use at last anal sex is significantly associated with HIV infection (adjusted AOR RDS: 0.47 95\%CI: $0.36-0.62), \quad \mathrm{p}<0.0001)$ ) adjusted on potentially confounding factors. It's about the age of less than 25 years (adjusted AOR RDS: 0.7; 95\%CI: 0.55-0. 90), $\mathrm{p}<0.0005$, education level (adjusted AOR RDS: $22.18,95 \% \mathrm{CI}$ : 9.49-59.75) $\mathrm{p}<0.0001$, lives in couple, (adjusted AOR RDS: $2.0195 \%$ CI: $1.54-2.63) \mathrm{p}<0.0001$; frequency of condom use with lubricant, (adjusted AOR RDS: 1.3; 95\% CI: 1.03-1.65) $\mathrm{p}<0.029$.

Table 4. Distribution of men who have sex with men according to their use of male condom and lubricant use.

\begin{tabular}{|c|c|c|c|}
\hline Variables & $\mathbf{n}$ & Unweighted (\%) & RDS-weighted (CI 95\%) \\
\hline Used the condom at every anal sex to protect himself $(\mathrm{N}=414)$ & 389 & 93.96 & $89.3(83.0-96.0)$ \\
\hline Has used the condom during the last anal intercourse with a man $(\mathrm{N}=414)$ & 307 & 74.15 & $71.5(63.3-80.0)$ \\
\hline Condom in the last 12 months has torn during sex $(\mathrm{N}=414)$ & 69 & 16.67 & $10.3(6.5-14.2)$ \\
\hline Yes & 210 & 50.72 & $45.9(37.2-54.6)$ \\
\hline No & 81 & 19.57 & $25.3(16.6-34.0)$ \\
\hline Never with a woman & 120 & 28.99 & $28.8(21.0-36.6)$ \\
\hline Saliva & 40 & 9.66 & $6.9(4.2-9.6)$ \\
\hline Vaseline, ointment & 67 & 16.18 & $17.0(10.2-23.8)$ \\
\hline Water-based lubricant & 274 & 66.18 & $66.2(57.3-75.1)$ \\
\hline Shea butter & 10 & 2.42 & $2.6(0.0-5.3)$ \\
\hline Body milk & 13 & 3.14 & $7.2(1.0-13.4)$ \\
\hline \multicolumn{4}{|l|}{ Frequency use of water-based lubricant $(\mathrm{N}=414)$} \\
\hline Always & 203 & 49.03 & $43.4(34.7-52.1)$ \\
\hline Sometimes & 153 & 36.96 & $41.3(32.5-50.1)$ \\
\hline \multicolumn{4}{|l|}{ Frequency use of condom together with lubricant $(\mathrm{N}=414)$} \\
\hline Both always together & 210 & 50.72 & $42.6(34.0-51.0)$ \\
\hline Both sometimes together & 204 & 49.28 & $57.3(49.0-66.0)$ \\
\hline \multicolumn{4}{|l|}{ Reasons for not using condoms with your partners $(\mathrm{N}=182)$} \\
\hline Reduces feelings & 58 & 14.01 & $33.4(21.5-45.5)$ \\
\hline Reduces pleasure & 68 & 16.43 & $37.1(23.7-50.6)$ \\
\hline Limited availability & 13 & 3.14 & $6.5(2.1-11.0)$ \\
\hline Faithfulness to my partner & 27 & 6.52 & $14.9(5.0-24.8)$ \\
\hline Know the HIV-status of my partner & 16 & 3.86 & $7.3(1.2-13.4)$ \\
\hline
\end{tabular}

Table 5. Bivariate and multivariate analysis of HIV sociodemographic and risk factors in men having sex with men in Benin.

\begin{tabular}{|c|c|c|c|c|c|c|c|c|}
\hline & \multicolumn{2}{|c|}{$\begin{array}{l}\text { HIV-Positive } \\
(\mathrm{n} 1=56)\end{array}$} & \multicolumn{2}{|c|}{$\begin{array}{l}\text { HIV-negative } \\
(\mathrm{n} 2=358)\end{array}$} & \multicolumn{2}{|c|}{ OR (Unweighted) } & \multicolumn{2}{|c|}{ OR (RDS Weighted) } \\
\hline & n & $\%$ & $\mathrm{n}$ & $\%$ & OR & CI 95\% & OR & CI $95 \%$ \\
\hline \multicolumn{9}{|l|}{ Age (years) } \\
\hline 25 and more & 20 & 35.7 & 124 & 34.6 & & & & \\
\hline under 25 & 36 & 64.3 & 234 & 65.2 & 0.95 & $0.52-1.71$ & 1.04 & $0.92-1.18$ \\
\hline \multicolumn{9}{|l|}{ Marital Status } \\
\hline Married/divorced & 5 & 8.93 & 20 & 5.59 & & & & \\
\hline Single & 51 & 91.07 & 338 & 94.41 & 0.6 & $0.22-1.68$ & 0.15 & $0.13-0.18$ \\
\hline
\end{tabular}




\begin{tabular}{|c|c|c|c|c|c|c|c|c|}
\hline & \multicolumn{2}{|c|}{$\begin{array}{l}\text { HIV-Positive } \\
(\mathrm{n} 1=56)\end{array}$} & \multicolumn{2}{|c|}{$\begin{array}{l}\text { HIV-negative } \\
(\mathrm{n} 2=358)\end{array}$} & \multicolumn{2}{|c|}{ OR (Unweighted) } & \multicolumn{2}{|c|}{ OR (RDS Weighted) } \\
\hline & $\mathbf{n}$ & $\%$ & $\mathrm{n}$ & $\%$ & OR & CI 95\% & OR & CI 95\% \\
\hline \multicolumn{9}{|l|}{ Educational Level } \\
\hline Out-of-school/primary & 4 & 9.3 & 39 & 90.7 & & & & \\
\hline Secondary & 29 & 17.0 & 142 & 83.0 & 1.99 & $0.73-7.01$ & 2.15 & $1.67-2.81$ \\
\hline High & 23 & 11.8 & 177 & 88.5 & 1.27 & $0.46-4.50$ & 1.11 & $0.85-1.45$ \\
\hline \multicolumn{9}{|l|}{ Living in couple } \\
\hline No & 36 & 94.9 & 259 & 88.4 & & & & \\
\hline Yes, with a woman & 2 & 5.3 & 34 & 11.6 & 0.42 & $0.10-1.84$ & 2.83 & $2.45-3.25$ \\
\hline Yes, with a man & 17 & 89.5 & 63 & 64.5 & 1.94 & $1.03-3.69$ & 0.07 & $0.03-0.12$ \\
\hline \multicolumn{9}{|l|}{ Sexual Orientation } \\
\hline Active/insertive & 24 & 43.6 & 200 & 56.8 & & & & \\
\hline Passive/receptive & 24 & 43.6 & 104 & 29.5 & 1.92 & $1.04-3.55$ & 1.39 & $1.21-1.59$ \\
\hline Versatile & 7 & 12.7 & 48 & 13.6 & 1.22 & $0.5-2.95$ & 1.48 & $1.19-1.83$ \\
\hline \multicolumn{9}{|l|}{ Homosexuality Type } \\
\hline Pure Homo & 38 & 14.6 & 222 & 85.4 & & & & \\
\hline Bisexual & 18 & 11.7 & 136 & 88.3 & 0.77 & $0.42-1.39$ & 1.14 & $1.01-1.29$ \\
\hline \multicolumn{9}{|c|}{ Has made his test and knows his result } \\
\hline No & 7 & 35.0 & 13 & 65 & & & & \\
\hline Yes & 33 & 12.7 & 226 & 83.7 & 0.27 & $0.10-0.77$ & 0.13 & $0.10-0.16$ \\
\hline \multicolumn{9}{|c|}{ Condom use during last anal sex with a male partner } \\
\hline No & 24 & 42.9 & 83 & 23.2 & & & & \\
\hline Yes & 32 & 57.1 & 275 & 76.8 & 0.4 & $0.22-0.72$ & 0.19 & $0.16-0.21$ \\
\hline \multicolumn{9}{|l|}{ Age at first intercourse (years) } \\
\hline $14-19$ & 36 & 15.9 & 91 & 84.1 & & & & \\
\hline $20-24$ & 20 & 10.7 & 167 & 89.3 & 0.64 & $0.35-1.13$ & 0.85 & $0.75-0.96$ \\
\hline \multicolumn{9}{|l|}{ Complete knowledge of HIV } \\
\hline No & 34 & 13.1 & 5 & 86.9 & & & & \\
\hline Yes & 34 & 14.2 & 133 & 85.9 & 0.1 & $0.61-1.94$ & 2.2 & $1.93-2.49$ \\
\hline \multicolumn{9}{|l|}{ Know his partner's HIV status } \\
\hline No & 30 & 13.2 & 197 & 86.8 & & & & \\
\hline Yes & 26 & 13.9 & 161 & 86.1 & 1.06 & $0.60-1.87$ & 2.29 & $2.02-2.61$ \\
\hline \multicolumn{9}{|c|}{ Frequency of condom use with lubricant } \\
\hline Both are always use together & 29 & 14.2 & 175 & 85.2 & & & & \\
\hline Not always together & 27 & 12.9 & 183 & 87.1 & 0.89 & $0.51-1.56$ & 0.69 & $0.61-0.79$ \\
\hline
\end{tabular}

Table 5. Continued.

\begin{tabular}{|c|c|c|c|c|c|c|}
\hline & \multicolumn{2}{|c|}{ Multivariate AOR (unweighted) } & \multirow{2}{*}{$\mathbf{P}$} & \multicolumn{2}{|c|}{ Multivariate RDS weighted AOR } & \multirow[b]{2}{*}{$\mathbf{p}$} \\
\hline & OR & CI 95\% & & OR & CI 95\% & \\
\hline \multicolumn{7}{|l|}{ Age (years) } \\
\hline \multicolumn{7}{|l|}{25 and more } \\
\hline under 25 & 1.31 & $0.56-3.04$ & 0.526 & 0.7 & $0.55-0.90$ & 0.005 \\
\hline \multicolumn{7}{|l|}{ Marital Status } \\
\hline \multicolumn{7}{|l|}{ Married/divorced } \\
\hline Single & 0.19 & $0.02-1.44$ & 0.123 & 0.006 & $0.003-0.013$ & 0.001 \\
\hline \multicolumn{7}{|c|}{ Educational Level } \\
\hline \multicolumn{7}{|c|}{ Out-of-school/primary } \\
\hline Secondary & 6.38 & $1.02-128.90$ & 0.101 & 78.33 & $33.64-211.18$ & 0.000 \\
\hline High & 4.1 & $0.66-82.49$ & 0.211 & 22.18 & $9.49-59.75$ & 0.000 \\
\hline \multicolumn{7}{|l|}{ Living in couple } \\
\hline \multicolumn{7}{|l|}{ No } \\
\hline Yes, with a woman & 2.14 & $0.88-5.09$ & 0.085 & 2.01 & $1.54-2.63$ & 0.000 \\
\hline Yes, with a man & 0.23 & $0.02-1.66$ & 0.209 & 0.002 & $0.0008-0.007$ & 0.000 \\
\hline \multicolumn{7}{|l|}{ Sexual Orientation } \\
\hline \multicolumn{7}{|l|}{ Active/insertive } \\
\hline Passive/receptive & 1.88 & $0.84-4.23$ & 0.122 & 0.65 & $0.50-0.84$ & 0.001 \\
\hline Versatile & 0.86 & $0.22-2.69$ & 0.804 & 1.27 & $0.91-1.77$ & 0.154 \\
\hline \multicolumn{7}{|l|}{ Homosexuality Type } \\
\hline \multicolumn{7}{|l|}{ Pure Homo } \\
\hline \multicolumn{7}{|l|}{ Bisexual } \\
\hline \multicolumn{7}{|c|}{ Has made his test and knows his result } \\
\hline \multicolumn{7}{|c|}{ No } \\
\hline Yes & 0.3 & $0.088-1.05$ & 0.054 & 0.34 & $0.23-0.50$ & 0.000 \\
\hline \multicolumn{7}{|c|}{$\begin{array}{l}\text { Condom use during last anal sex with a male partner } \\
\text { No }\end{array}$} \\
\hline Yes & 0.62 & $0.26-1.49$ & 0.267 & 0.47 & $0.36-0.62$ & 0.000 \\
\hline
\end{tabular}




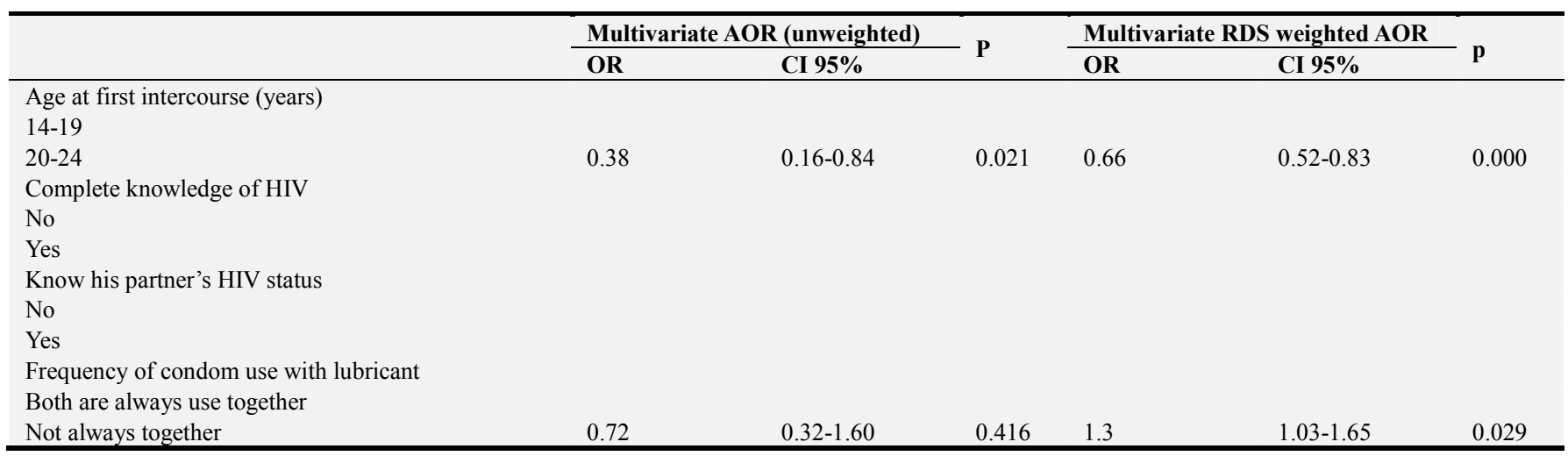

\section{Discussion}

\subsection{Strengths and Assets of the Study}

The study highlighted the very high prevalence of HIV infection among the MSM population compared to the general population (almost 20 times higher) [34]. Several factors such as age, condom use and the use of condoms and lubricant gels are associated with this high prevalence of HIV infection among MSM. It shows the contributory nature of MSM to new HIV infections at the national level by confirming their status as key populations. This situation challenges the actors of the national response to HIV infection for setting up specific programs with a high impact of prevention, such as combined prevention (pre-exposure prophylaxis) and HIV infection for the benefit of this target group.

\subsection{Comparison with Other Studies in Terms of Similarities and Differences}

More than $60 \%$ of MSM are under 25 years of age and this result is similar to those found in several sub-Saharan African countries [10, 11, 35-37]. Young homosexuals currently tend to experience more easily their sexual orientation, thanks to the conducive global environment for the defense and protection of human rights and the easy accessibility to new communication and information technologies. This facilitating and favorable environment would explain this result $[1,4,14]$. A significant proportion of MSM reported being the receptive partner during anal sex. This result is comparable to that found in other studies in Malawi [5] and Cameroon [10] and shows the increased risk of HIV exposure associated with unprotected receptive anal sex (RDS-weighted OR: 0.65 , 95\%CI: 0.50-0.84), $\mathrm{P}<0.001$. One out of five MSM is HIV-positive and this is significantly higher than HIV prevalence in the general population $[11,25]$ but consistent with that observed in most similar studies and ranges from $17.4 \%$ to 25.5 in the following countries, Cameroon, Togo and Nigeria [4, 10, 35]. The high level of HIV prevalence can be explained by anal sexual risk factors, low coverage of interventions in prevention packages and by the social exclusion and "hidden" lifestyle of homosexuals due to discrimination and stigmatization displayed by the general population towards them $[11,36,38]$. Bisexuality is shared by $17 \%$ of MSM who live transversally their sexual lives in the general population and are thus a significant source of new infections $[3,4,39]$. This bisexual behavior is sometimes a constraint for MSM who are compelled to hide to live peacefully their homosexuality in culturally hostile societies, but they say they never feel comfortable [8, 18, 40]. This situation varies from one country to another and ranges from $14.6 \%$ to $58.9 \%$ in Togo, Uganda, Mozambique and Gambia [35, 38, 39, 41] and is closely linked to the high stigmatization of this target among the general population. The minimum age at first anal intercourse with another man is 19 years, which indicates early anal intercourse. It's 15 years in Mozambique [39]. It should be noted in this context that there are very few HIV prevention programs specific to this age group, to address this issue [44, 45]. Very few MSM in the study use condoms with lubricant, which are true means of preventing HIV infection and especially preventing condom tearing and mucosal damages (potential transmission opportunity, if the partner is HIV-positive) during anal sex. For MSM who consistently use condoms and lubricants, they are 1.3 times more protected than those who sometimes use both OR: 1.3 (95\% CI: 1.03-1.65). Access to lubricant is difficult for MSM populations, only $11.3 \%$ have access to it in Gambia and $16.8 \%$ use water-based lubricants, compared to $43.04 \%$ in Benin [38]. Condom use by MSM at last anal intercourse is $71.5(62.4-80.6)$ compared to $66.2 \%$ in a study realized in Gambia, $76.0 \%(70.0-81.2)$ in Mali and 76.1 (70.5-81.2) in Mozambique, indicating an average protection level against HIV infection for MSM. But this performance falls when it comes to using condoms combined with lubricating gels. With regard to the level of complete knowledge on HIV infection, less than half of MSM 45.6\% (35.2 - 56.1) have it, and those with a level of complete knowledge are 2.2 times more likely to be protected from HIV infection than others. They can also benefit from new combination prevention strategies such as Pre-Exposure Prophylaxis of HIV infection in men who have sex with men (PrEP) and/or preventive treatment of infected people (screening and treatment).

\subsection{Limitations}

The results of our study concerned mostly young MSM 
with a relatively high level of education; this may not reflect the entire MSM population, so there may be a problem with generalizing the study results, but with the Responding Driven Sampling (RDS) method, and the characteristics of initial seeds selection, this bias is minimized $[14,17]$. This is a cross-sectional study, and it does not allow a causal link between the associations with HIV infection [39, 46, 47], but this study has the advantage of presenting, in a descriptive way, the situation of HIV infection among MSM population. MSM are people who live hidden, by reason of stigma and discrimination, especially in African countries, which may limit their participation in the study. But the fact that we have worked with the two major networks and with all MSM associations and the use of RDS [14, 17] have completely reduced this selection bias.

\section{Conclusion}

This bio-behavioral study showed a high prevalence of HIV infection among MSM populations in Benin with strongly associated behavioral factors. These results of the study call for the national response system to HIV infection at several levels: managerial, design and implementation of interventions for the benefit of the MSM target, taking into account the specificity of this target in a complex social, cultural, religious and legal environment, monitoring and evaluation of interventions in order to verify whether it really allows, from year to year, the reversal of the trend of the HIV epidemic in the population in general and in particular in the MSM population.

With regard to the managerial level: it is urgent to include this target in the national epidemiological surveillance system and to give it all the necessary attributes. As for the design of interventions in an environment marked by stigma and discrimination, particular emphasis must be placed on projects and programs that are accepted by communities and that will make it possible, in time and space, to remove socio-cultural, religious and legal barriers to access to the HIV prevention and care package. Interventions for this key population for HIV infection must be designed by experts into a comprehensive package of high-impact, cost-effective interventions that can reverse the epidemic among this population of MSM.

\section{References}

[1] Baral S, Sifakis F, Cleghorn F, Beyrer C: Elevated risk for HIV infection among men who have sex with men in low- and middle-income countries 2000-2006: a systematic review. PLoS Med 2007, 4 (12): e339.

[2] International M: Ghana 2014 Demographic and Health Survey Demographic and Health Survey HIV Prevalence, page 245. 2014.

[3] Beyrer C, Sullivan P, Sanchez J, Baral SD, Collins C, Wirtz AL, Altman D, Trapence G, Mayer K: The increase in global HIV epidemics in MSM. AIDS 2013, 27 (17): 2665-2678.
[4] Merrigan M, Azeez A, Afolabi B, Chabikuli ON, Onyekwena O, Eluwa G, Aiyenigba B, Kawu I, Ogungbemi K, Hamelmann C: HIV prevalence and risk behaviours among men having sex with men in Nigeria. Sex Transm Infect 2011, 87 (1): 65-70.

[5] Wirtz AL, Jumbe V, Trapence G, Kamba D, Umar E, Ketende S, Berry M, Stromdahl S, Beyrer C, Baral SD: HIV among men who have sex with men in Malawi: elucidating HIV prevalence and correlates of infection to inform HIV prevention. J Int AIDS Soc 2013, 16 Suppl 3: 18742.

[6] Rispel LC, Metcalf CA, Cloete A, Reddy V, Lombard C: HIV prevalence and risk practices among men who have sex with men in two South African cities. J Acquir Immune Defic Syndr 2011, 57 (1): 69-76.

[7] Baral S, Trapence G, Motimedi F, Umar E, Iipinge S, Dausab F, Beyrer C: HIV prevalence, risks for HIV infection, and human rights among men who have sex with men (MSM) in Malawi, Namibia, and Botswana. PLoS One 2009, 4 (3): e4997.

[8] Keshinro B, Crowell TA, Nowak RG, Adebajo S, Peel S, Gaydos CA, Rodriguez-Hart C, Baral SD, Walsh MJ, Njoku OS et al: High prevalence of HIV, chlamydia and gonorrhoea among men who have sex with men and transgender women attending trusted community centres in Abuja and Lagos, Nigeria. J Int AIDS Soc 2016, 19 (1): 21270.

[9] Lloyd J, Papworth E, Grant L, Beyrer C, Baral S: Systematic review and meta-analysis of HIV prevalence among men in militaries in low income and middle income countries. Sex Transm Infect 2014, 90 (5): 382-387.

[10] Park JN, Papworth E, Kassegne S, Moukam L, Billong SC, Macauley I, Yomb YR, Nkoume N, Mondoleba V, Eloundou J et al: HIV prevalence and factors associated with HIV infection among men who have sex with men in Cameroon. J Int AIDS Soc 2013, 16 Suppl 3: 18752.

[11] Dahoma M, Johnston LG, Holman A, Miller LA, Mussa M, Othman A, Khatib A, Issa R, Kendall C, Kim AA: HIV and related risk behavior among men who have sex with men in Zanzibar, Tanzania: results of a behavioral surveillance survey. AIDS Behav 2011, 15 (1): 186-192.

[12] Sanders EJ, Graham SM, Okuku HS, van der Elst EM, Muhaari A, Davies A, Peshu N, Price M, McClelland RS, Smith AD: HIV-1 infection in high risk men who have sex with men in Mombasa, Kenya. AIDS 2007, 21 (18): 2513-2520.

[13] Wade AS, Kane CT, Diallo PA, Diop AK, Gueye K, Mboup S, Ndoye I, Lagarde E: HIV infection and sexually transmitted infections among men who have sex with men in Senegal. AIDS 2005, 19 (18): 2133-2140.

[14] Kendall C, Kerr LR, Mota RM, Cavalcante S, Macena RH, Chen S, Gaffga N, Monterosso E, Bastos FI, Serrano D: Population size, HIV, and behavior among MSM in Luanda, Angola: challenges and findings in the first ever HIV and syphilis biological and behavioral survey. $\mathrm{J}$ Acquir Immune Defic Syndr 2014, 66 (5): 544-551.

[15] CNLS/Benin: Plan Strategique National de Lutte contre le Sida (PSN) 2015-2017; CNLS-Benin 2015.

[16] Wejnert C, Le B, Rose CE, Oster AM, Smith AJ, Zhu J, Gabriela Paz-Bailey for the NSG: HIV infection and awareness among men who have sex with men-20 cities, United States, 2008 and 2011. PLoS One 2013, 8 (10): e76878. 
[17] Finlayson TJ, Le B, Smith A, Bowles K, Cribbin M, Miles I, Oster AM, Martin T, Edwards A, Dinenno E et al: HIV risk, prevention, and testing behaviors among men who have sex with men--National HIV Behavioral Surveillance System, 21 U.S. cities, United States, 2008. MMWR Surveill Summ 2011, 60 (14): 1-34.

[18] Smith AD, Tapsoba P, Peshu N, Sanders EJ, Jaffe HW: Men who have sex with men and HIV/AIDS in sub-Saharan Africa. Lancet 2009, 374 (9687): 416-422.

[19] Pitts MK, Couch MA, Smith AM: Men who have sex with men (MSM): how much to assume and what to ask? Med J Aust 2006, 185 (8): 450-452.

[20] Lemeshow SKLS: DETERMINATION DE LA TAILLE D'UN ECHANTILLON DANS LES ETUDES SANOMETRIQUES Manuel pratique. ISBN 9242544051 (Classification NLM: WA 950) Organisation mondiale de la Sante, 1991.

[21] Wirtz AL, Trapence G, Kamba D, Gama V, Chalera R, Jumbe V, Kumwenda R, Mangochi M, Helleringer S, Beyrer C et al: Geographical disparities in HIV prevalence and care among men who have sex with men in Malawi: results from a multisite cross-sectional survey. Lancet HIV 2017, 4 (6): e260-e269.

[22] Holland CE, Kouanda S, Lougue M, Pitche VP, Schwartz S, Anato S, Ouedraogo HG, Tchalla J, Yah CS, Kapesa L et al: Using Population-Size Estimation and Cross-sectional Survey Methods to Evaluate HIV Service Coverage Among Key Populations in Burkina Faso and Togo. Public Health Rep 2016 , 131 (6): 773-782.

[23] Stahlman S, Johnston LG, Yah C, Ketende S, Maziya S, Trapence G, Jumbe V, Sithole B, Mothopeng T, Mnisi Z et al: Respondent-driven sampling as a recruitment method for men who have sex with men in southern sub-Saharan Africa: a cross-sectional analysis by wave. Sex Transm Infect 2016, 92 (4): 292-298.

[24] Stahlman S, Grosso A, Ketende S, Mothopeng T, Taruberekera N, Nkonyana J, Mabuza X, Sithole B, Mnisi Z, Baral S: Characteristics of men who have sex with men in southern Africa who seek sex online: a cross-sectional study. J Med Internet Res 2015, 17 (5): e129.

[25] Baral SD, Ketende S, Mnisi Z, Mabuza X, Grosso A, Sithole B, Maziya S, Kerrigan DL, Green JL, Kennedy CE et al: A cross-sectional assessment of the burden of HIV and associated individual- and structural-level characteristics among men who have sex with men in Swaziland. J Int AIDS Soc 2013, 16 Suppl 3: 18768 .

[26] Wirtz AL, Clouse E, Veronese V, Thu KH, Naing S, Baral SD, Beyrer C: New HIV testing technologies in the context of a concentrated epidemic and evolving HIV prevention: qualitative research on HIV self-testing among men who have sex with men and transgender women in Yangon, Myanmar. J Int AIDS Soc 2017, 20 (1): 21796.

[27] FHI: Enquêtes de Surveillance Comportementale: Guide pour enquêtes répétées de surveillance comportementale au sein de populations exposées au VIH. Projet financé par le US Agency for International Development et le Department for International Development, United Kingdom (DFID) Accord CNTR 970395 AC 2000 Family Health International Version française, septembre 20022002.

[28] OMS/ONUSIDA: Directives pour la surveillance des populations les plus exposées au VIH. Organisation mondiale de la Santé, Département of VIH/sida 20, avenue Appia CH-
1211 Genève 27 Suisse Courriel: hiv-aids@whoint, http://wwwwhoint/hiv/fr 2011.

[29] OMS/ONUSIDA: lignes directrices pour la surveillance du vih chez les femmes enceintes en consultation prénatale à partir des données programmatiques de routine, groupe de travail global onusida/oms sur la surveillance pour le vih/sida et des ist. Organisation mondiale de la Santé, Département du VIH/SIDA 20, avenue Appia 1211 Genève 27 Suisse Courriel: hiv-aids@whoint wwwwhoint/hiv 2015.

[30] ONUSIDA: Guide de teminologie de l'ONUSIDA, P: 40, 20 Avenue Appia CH-1211 Genève 27 Suisse +41 227913666 unaids.org. 2011.

[31] K JLS: Echantillonnage déterminé selon les répondants pour les populations difficiles à joindre, Methodological Innovations Online 5 (2) 38-48. 2010.

[32] McKnight C, Des Jarlais D, Bramson H, Tower L, Abdul-Quader AS, Nemeth C, Heckathorn D: Respondent-driven sampling in a study of drug users in New York City: notes from the field. J Urban Health 2006, 83 (6 Suppl): i54-59.

[33] Sabin LGJaK: Échantillonnage déterminé selon les répondants pour les populations difficiles à joindre. Methodological Innovations Online (2010) 5 (2) 38-48 2010.

[34] Macro International IB: Enquete Démographique et de Sante (EDS/DHS 2011-2012). 2011-2012.

[35] Ekouevi DK, Dagnra CY, Goilibe KB, Tchounga B, Orne-Gliemann J, Salou M, Anato S, Prince-David M, Pitche VP: [HIV seroprevalence and associated factors among men who have sex with men in Togo]. Rev Epidemiol Sante Publique 2014, 62 (2): 127-134.

[36] Lahuerta M, Patnaik P, Ballo T, Telly N, Knox J, Traore B, Doumbia S, Hakim A: HIV Prevalence and Related Risk Factors in Men Who Have Sex with Men in Bamako, Mali: Findings from a Bio-behavioral Survey Using Respondent-Driven Sampling. AIDS Behav 2018, 22 (7): 2079-2088.

[37] Vu L, Andrinopoulos K, Tun W, Adebajo S: High levels of unprotected anal intercourse and never testing for HIV among men who have sex with men in Nigeria: evidence from a cross-sectional survey for the need for innovative approaches to HIV prevention. Sex Transm Infect 2013, 89 (8): 659-665.

[38] Mason K, Ketende S, Peitzmeier S, Ceesay N, Diouf D, Loum J, Deen D, Drame F, Baral S: A cross-sectional analysis of population demographics, HIV knowledge and risk behaviors, and prevalence and associations of HIV among men who have sex with men in the Gambia. AIDS Res Hum Retroviruses 2013, 29 (12): 1547-1552.

[39] Nala R, Cummings B, Horth R, Inguane C, Benedetti M, Chissano M, Sathane I, Young P, da Silva D, Mirjahangir J et al: Men who have sex with men in Mozambique: identifying a hidden population at high-risk for HIV. AIDS Behav 2015, 19 (2): 393-404.

[40] Van der Elst EM, Smith AD, Gichuru E, Wahome E, Musyoki H, Muraguri N, Fegan G, Duby Z, Bekker LG, Bender B et al: Men who have sex with men sensitivity training reduces homoprejudice and increases knowledge among Kenyan healthcare providers in coastal Kenya. J Int AIDS Soc 2013, 16 Suppl 3: 18748 . 
[41] Peitzmeier S, Mason K, Ceesay N, Diouf D, Drame F, Loum J, Baral S: A cross-sectional evaluation of the prevalence and associations of HIV among female sex workers in the Gambia. Int J STD AIDS 2014, 25 (4): 244-252.

[42] Hladik W, Barker J, Ssenkusu JM, Opio A, Tappero JW, Hakim A, Serwadda D, Crane Survey G: HIV infection among men who have sex with men in Kampala, Uganda--a respondent driven sampling survey. PLoS One 2012, 7 (5): e38143.

[43] Sathane I, Horth R, Young P, Inguane C, Nala R, Miranda AE, Lane T, Raymond HF, Cummings B, McFarland W: Risk Factors Associated with HIV Among Men Who Have Sex Only with Men and Men Who Have Sex with Both Men and Women in Three Urban Areas in Mozambique. AIDS Behav 2016, 20 (10): 2296-2308.

[44] Aho J, Hakim A, Vuylsteke B, Semde G, Gbais HG, Diarrassouba M, Thiam M, Laga M: Exploring risk behaviors and vulnerability for HIV among men who have sex with men in Abidjan, Cote d'Ivoire: poor knowledge, homophobia and sexual violence. PLoS One 2014, 9 (6): e99591.

[45] Beyrer C, Baral SD, van Griensven F, Goodreau SM, Chariyalertsak S, Wirtz AL, Brookmeyer R: Global epidemiology of HIV infection in men who have sex with men. Lancet 2012, 380 (9839): 367-377.

[46] Baral S, Sifakis F, Peryskina A, Mogilnii V, Masenior NF, Sergeyev B, Deobald I, Wirtz AL, Beyrer C: Risks for HIV infection among gay, bisexual, and other men who have sex with men in Moscow and St. Petersburg, Russia. AIDS Res Hum Retroviruses 2012, 28 (8): 874-879.

[47] Sheehy M, Tun W, Vu L, Adebajo S, Obianwu O, Karlyn A: High levels of bisexual behavior and factors associated with bisexual behavior among men having sex with men (MSM) in Nigeria. AIDS Care 2014, 26 (1): 116-122. 